\title{
Tables des matières
}

\section{TOME I}

Avertissement $\ldots \ldots \ldots \ldots \ldots \ldots \ldots \ldots \ldots \ldots \ldots \ldots \ldots$ VII

Tableau des auteurs $\ldots \ldots \ldots \ldots \ldots \ldots \ldots \ldots \ldots \ldots \ldots \ldots \ldots \ldots$

Bibliographie $\ldots \ldots \ldots \ldots \ldots \ldots \ldots \ldots \ldots \ldots \ldots \ldots \ldots \ldots \ldots \ldots \ldots$

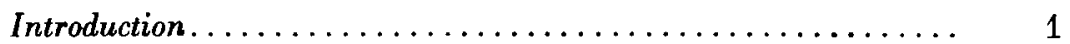

CHAPITRE PREMIER. - Aux sources de la géographie arabe : les sciences nouvelles et les sciences traditionnelles........ 7

La mathématique de la Création.............. 7

Les sciences de la terre : la géodésie, l'astrologie et l'élaboration du genre cartographique de la șürat al-ard..... 10

Les sciences de la terre : la physique du globe........ 14

Les sciences de la terre : les êtres vivants.......... 16

Science grecque et géographie................ 17

Les sciences morales : l'éthique................. 19

Les sciences politiques : la technique du pouvoir........ 20

La tradition : les sciences philologiques. Géographie, iranisme et langue arabe.................... 23

La tradition : les sciences religieuses............. 25 


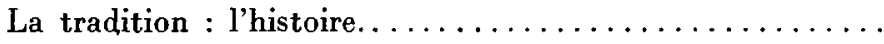

Histoire, géographie et tradition. Science grecque et science arabe

CHAPITRE II. - Les orientations décisives $d u I I I \mathrm{e} / I X^{\mathbf{e}}$ siècle ; géographie et adab; Gähiz̧ et Ibn Qutayba........... 35

Le problème de l'adab...................... 35

Ğāhì : son importance dans l'élaboration de la géographie

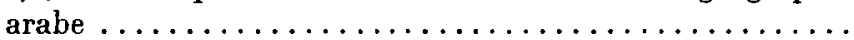

Le Kitāb at-tarbī' wa t-tadwir : une inquiétude nouvelle... .

Le Kitāb al- hayaswān : l'ébauche d'une géographie humaine.

Le Kitāb al-amșār wa 'ağà'ib al- buldān : géographie et tradi-

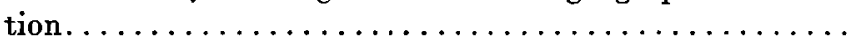

Ibn Qutayba : les exigences de l'orthodoxie..........

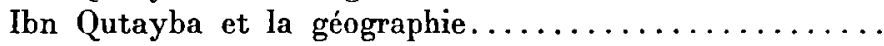

CHAPITRE III. - Les préoccupations techniques : la cartographie de la șūrat al-ard et son évolution; la littérature administrative et son développement; les enquêtes commerciales.......

Définition et données de la șürat al-ard............

L'école de Kindī et les développements de la şūra : Sarabsi, Ibn Serapion, Balhi. ......................

Naissance de la géographie administrative............

Le pionnier de la géographie administrative : Ibn Hurdād-

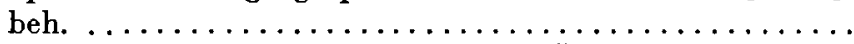

Un continuateur d'Ibn Hurdādbeh : Gayhānī.........

Qudāma b. Ğa'far ou la science administrative totale...

Ya'qūbì et la littérature administrative............

Les thèmes administratifs en dehors de la littérature admi-

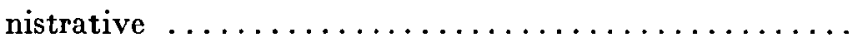

Survivance de la géographie administrative et de la șürat

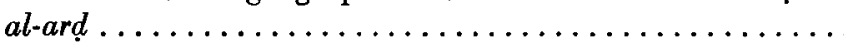

Les catalogues de prix et de denrées............ 108

CHAPITRE IV. - Les gens du voyage............ 113

Les vocations........................ 113

Le commerce et les routes maritimes de l'Océan Indien : la Relation de la Chine et de l'Inde............... 116

Abũ Zayd as-Sīrāfī : la Relation revue et complétée .... 121

Les Merveilles de l'Inde.................... 127

La route du nord et les voyageurs officiels : Ibn Faḍlān. 132 
La route du nord : Abū Dulaf Mis'ar; le voyage réel et le voyage imaginaire..................... 139

Les routes du nord-ouest et du sud : l'Europe et l'Afrique. 145

Les débuts d'une " géographie spirituelle des intercessions". 149

Conclusion $\ldots \ldots \ldots \ldots \ldots \ldots \ldots \ldots \ldots \ldots \ldots \ldots \ldots \ldots$

CHAPITRE V. - Ibn al-Faqih ou la géographie que par l'adab. 153

L'cuvre d'Ibn al-Faqih et le problème de sa transmission. 153

Traits généraux de l'œuvre d'Ibn al-Faqīh........... 160

Sources, composantes et thèmes du Kitäb al-buldān..... 165

Techniques et mécanismes dans l'œuvre d'Ibn al-Faqih.... 171

La "science des pays ": une science à sa manière...... 177

Géographie humaine ou humanisme géographique ?..... 182

Conclusion ............................. 187

CHAPITRE VI. - La géographie sans les géographes : encyclopédistes, polygraphes, historiens et autres.............

Les encyclopédistes : Ibn Rusteh............... 192

L' " imam " de l'encyclopédisme : Mas'ūdī.......... 202

Les encyclopédistes : Maqdisi et le Liore de la création et de l'histoire......................... 212

L'encyclopédie des "Frères de la Sincérité 》 (Ihwān aṣ-șafă $) .218$

Deux cas marginaux : Huwārizmì et Bīrūni.......... 222

Les polygraphes........................ 228

Géographie et littérature; le cas de la stylistique et de la bibliographie ....................... 235

La géographie et l'histoire $\ldots \ldots \ldots \ldots \ldots \ldots \ldots \ldots \ldots .239$

CHAPITRE VII. - Les monographies et les dictionnaires..... 243

La littérature arabique : ses diverses composantes...... 244

La géographie de la Péninsule arabique : Hamdānī..... 247

La littérature provinciale sous le signe de l'histoire..... 253

La littérature provinciale : les calendriers.......... 257

La littérature provinciale : l'Espagne et l'Afrique du Nord. 259

Les répertoires, premières ébauches des dictionnaires :

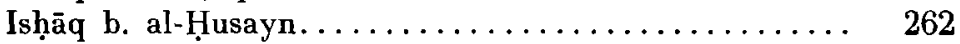

CHAPITRE VIII. - L'avènement d'une véritable géographie humaine : les masālik wa l-mamālik et l'étude de la terre des hommes 
700 Géographie arabe et représentation du monde

Pages

Le siècle des masälik wa l-mamälik............. 268

Définition du genre des masälik wa l-mamālik : un héritage, mais revêtu d'un sens nouveau................ 275

Définition des masālik wa l-mamālik (suite) : la géographie

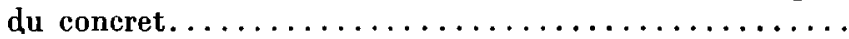

Définition des masālik wa l-mamälik (suite) : la géographie humaine............................

Définition des masālik wa l-mamālik (fin) : un genre littéraire.

Ya'qūbì : une ébauche réussie des masālik wa l-mamālik.

Iștahnrī : les masālik wa l-mamälik enfin constitués comme

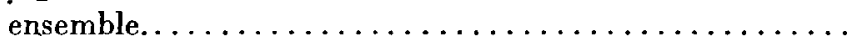

Ibn Hawqal, légataire d'Ișțahrī ; la géographie des commercants missionnaires....................... 299

Un mal-connu : Muhallabi................... 309

Muqaddasi et son temps.................. 313

Muqaddasī et son œuvre : l'apogée des masālik wa l-mamālik ................................ 322

CHAPITRE IX. - La géographie dans son environnement... 331

Le contexte économique : commerce et géographie...... 332

Le contexte politique : les modes d'une géographie impériale. $\quad 335$

Le contexte social et religieux : une littérature urbaine de sang-mêlé, en marge de l'orthodoxie.......... 338

Un public modelé par une culture commune......... 342

L'esprit d'une classe : science, art et littérature....... 347

L'esprit d'une classe : art de vivre et savoir-vivre...... 350

L'esprit de référence et l'esprit de système.......... 354

Langue et style : expression médiane et expression artistique.............................. 358

Conclusion ........................ 363

Appendice I (comparaison des textes d'Iṣțahrī et d'Ibn Hawqal). 367

Appendice II (calendriers)................... 391

Appendice III (la littérature géographique iranienne) ...... 397

Addenda. . . . ........................ 401

Index géographique..................... 407

Index historique....................... 411

Index des termes étrangers. .................. 419

Table des matières........................ 423 


\section{TOME II}

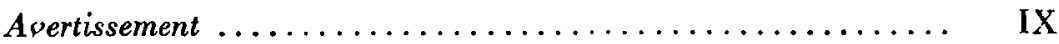

Sources et ouprages de référence................. XXI

Liste des auteurs (abrésiations) ................. XXV

Avant-propos............................ 1

CHAPITRE PREMIER. - La terre indivise........... 3

La terre et l'univers.................... 4

L'ensemble Terre : vie, mort et résurrection......... 10

L'espace Terre : formes, dimensions, représentation..... 16

Le domaine Terre : limites réelles et mythiques....... 20

CHAPITRE II. - La terre partagée.............. 31

Terre étoilée, ou impératifs et conflits de la géopolitique... . 31

Terre écartelée : Hamdānī et la cartographie astrologique.. 33

Terre découpée : les sept climats de la Grèce......... 56

Les rois du monde et leurs peuples : unité et diversité de la

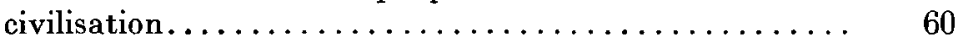

Le quatrième climat : l'Irak successeur de Babylone...... 68

CHAPITRE III. - L'Extrême-Orient, ou de grandes civilisations

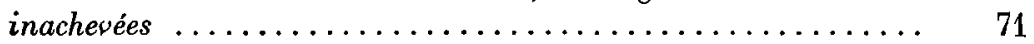

La littérature exotique : les affaires et l'Islam........ 72

La littérature exotique: des paysages masqués parles hommes. $\quad 73$

L'Extrême-Orient : des marchands aux marins et des marins

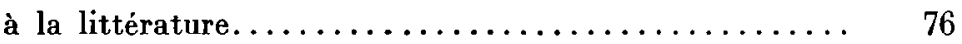

Une carte sommaire de l'Asie................ 78

Civilisation et territoire : Inde et Chine, massivement.... 82

Physionomie d'un continent................. 85

La nature : une terre précieuse, de pierre et de métal..... 88

La nature : le bestiaire sauvage............... 90

La nature : le bestiaire domestique et l'éléphant........ 94

La nature : des arbres et des plantes utiles.......... 98

Les hommes : simplicité et incertitude des thèmes raciaux.. 100 
Les hommes : les thèmes des échanges........... 103

Les hommes : le pouvoir et ses principes.......... 106

Les hommes : la vie publique................ 111

Les hommes : identités et différences des civilisations.... 114

Les hommes : mours et morale................. 117

Les hommes : la religion.................... 121

Conclusion. .......................... 124

CHAPITRE IV. - L'Afrique Noire, ou un continent entrevu. . . 127

Des savants péremptoires et des marchands tenaces..... 128

Incertitudes africaines.................... 131

Blason d'un continent : d'or au chevron de montagnes et de dunes............................ 134

L'Afrique et son fleuve : sources du Nil et " pays noir »... 135

La négritude : préjugés et contre-attaques......... 140

Panorama des pays : émergence du Soudan occidental... 147

Panorama des pays : les régions du haut Nil : la Nubie... 153

Panorama des pays : les régions du haut Nil : les Bedja et

l'A byssinie........................... 161

Panorama des pays : les Zanğ de l'océan Indien......... 167

La terre d'Afrique : une mine................ 173

Les êtres de l'Afrique : sous le signe ambigu du soleil..... 176

Le bestiaire d'Afrique : naturel, fantastique et originalité.. 177

Échantillons de la flore africaine............... 185

Les hommes : sauvagerie et sociétés............. 188

Les hommes : religion et paganisme, coutume et nature... 195

Quelques percées sur les techniques et le commerce..... 199

Conclusion. .......................... 201

CHAPITRE V. - Les grands espaces ouralo-altä̈ques...... 203

Où l'homme est mieux connu que son pays.......... 204

A l'est, avec les Tures des montagnes : les Tugiugiuz.... 205

A l'est, avec les Tures des montagnes : les Qarluq..... 208

A l'est, avec les Turcs des montagnes : Yag̀mā, Šigil, Tuhs 210

A l'est, avec les Turcs des montagnes : les Kirghiz....... 212

A l'ouest, avec les Turcs des plaines : Kïmāk et Qipčaq.... 213

A l'ouest, avec les Turcs des plaines : les Bašğirt........ 214

A l'ouest, avec les Turcs des plaines : les Petchénègues.... 216

A l'ouest, avec les Turcs des plaines : les Ǵuzz; demi-vérités d'une frontière........................ 218

Les Guzz, seuls vrais Turcs des plaines, peut-être...... 221

D'autres Turcs, en ordre dispersé.............. 223 
Le pays turc......................... 225

L'homme turc.......................... 230

La vie quotidienne...................... 233

La coutume familiale..................... 235

Société et religion : entre l'unité et l'éparpillement..... 237

Le Turc face au monde.................... 240

Du commerce à la guerre.................... 244

Conclusion : le Turc et l'Islam............... 248

CHAPITRE VI. - L'Europe de l'Est.............. 257

Le Caucase oriental. . . . . . . . . . . . . . . . 259

Le Caucase central : Avars et Alains.............. 265

Le Caucase de l'ouest et du sud............... 267

Tout le Caucase......................... 269

Les Bulgares de la Volga..................... 272

Les Bulgares chez eux : Ibn Faḍlān............. 277

L'État et la société bulgares................ 279

Le pays bulgare : le temps perturbé............. 283

Les Burtās. . ......................... 285

Les Khazars : le pays et l'histoire. . . . . . . . . . . 286

La vie au pays khazar..................... 289

La société khazare. . . . . . . . . . . . . . . . 293

L'Etat khazar : le symbolisme royal............... 295

Où l'on retrouve, entre Don et Danube, des peuples connus : Petchénègues et Magyars............... 300

Vers l'Europe danubienne : sous le nom de Velendre, une autre Bulgarie......................... 303

Les Slaves : un bloc envahissant............... 309

Sur divers peuples slaves................... 312

L'itinéraire d'Ibrāhīm b. Ya'qūb. . . . . . . . . . . . . 316

Pays et gens du froid..................... 319

La vie quotidienne..................... 323

Où la mort fascine plus que la vie............. 325

La religion slave....................... 327

Russes, Varègues, Wìsū................... 331

Les Russes vus de loin. .................... 334

Les Russes vus de près : Ibn Fạ̣lān . . . . . . . . . . 336

La mort russe.......................... 338

CHAPITRE VII. - L'Europe de l'Ouest.............. 343

Au Nord : les Normands.................... 345

Bretagne et autres îles.................... 348 
L'Espagne infidèle : des Francs aux Gascons........ 349

L'Espagne infidèle : Galiciens et vue d'ensemble....... 352

Les Francs : un grand peuple, un territoire incertain..... 354

Les Francs : notations discrètes et vues d'ensemble..... 356

Un itinéraire en pays franc................. 359

Les Burgondes......................... 362

L'Italie moins Rome : Francs ou Lombards ?.......... 362

Rome et les Rūm..................... 368

Rome : d'abord une histoire................ 370

Rome et ses merveilles.................... 372

De quelques îles méditerranéennes............. 377

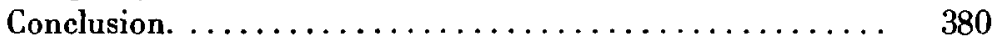

CHAPITRE VIII. - Au plus près du monde musulman : Byzance ......................... 381

Les géographes face à Byzance............... 382

Le monde des informateurs. ................ 383

Byzance voisine et lointaine................. 387

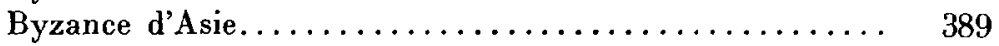

Le pays organisé : les thèmes................ 391

Les thèmes après Ibn $\underline{H} u r d a ̄ d b e h \ldots \ldots \ldots \ldots \ldots \ldots \ldots .396$

Les thèmes chez Mas'üdi.................. 400

Un essai de cartographie : Ibn Hawqal............ 405

Byzance, ville des villes, et son " fleuve $" . . \ldots \ldots \ldots \ldots \ldots \quad 411$

Byzance : la mer et les murs, la pierre et l'eau.......... 417

Byzance : des églises et des palais................ 422

Byzance et ses merveilles................... 426

L'Empereur : une histoire.................. 428

L'institution impériale................... 434

Les merveilles de l'audience impériale........... 437

L'entourage de l'Empereur.................. 440

De quelques particularités de l'administration byzantine. $\quad 445$

Byzance : une Église ou l'Église ?.............. 451

L'Église : organisation et culte.............. 456

Christianisme byzantin et Islam............... 458

Une Byzance d'où la vie quotidienne est absente....... 461

L'espace et l'histoire..................... 463

Byzance et la Grèce...................... 466

Byzance et l'Islam : le cas des prisonniers.......... 470

Byzance et l'Islam; le bilan d'une histoire : la frontière... . 472

La fin de Byzance ou la fin de l'Islam ? .......... 476 
CHAPITRE IX. - Au plus loin du monde musulman: les pays de la légende.......................... 483

De quelques caractéristiques du merveilleux......... 484

Les îles. ............................ 485

Les îles chez Ibrāhīm b. Waṣif Šãh............ 488

Les pays du métal...................... 490

Le monde des femmes..................... 493

Le Nord légendaire...................... 495

Au bout de l'Asie centrale : Gog et Magog............ 497

Gog et Magog : le récit de Sallām l'Interprète........... 498

Au pays de Gog et Magog................... 503

Gens de Gog et Magog................... 507

Quand l'Est et le Sud se confondent : le Wāq-Wāq..... 511

CHAPITRE X. - Les colonies musulmanes à l'étranger.... . 515

Activités et organisation.................. 518

Colonie musulmane et société d'accueil.............. 519

Islam et langue arabe.................. 522

Colonies musulmanes et monde musulman......... 523

CHAPITRE XI. - Le monde musulman sur la terre........ 525

Définition du " domaine " de l'Islam : la mamlaka....... 525

La mamlaka, pôle à deux ou trois pôles........... 528

La mamlaka face à la mer................. 530

Sur les terres : la mamlaka installée............. 533

Frontières tranquilles et marches mouvementées....... 535

Frontière et légende...................... 539

Index des noms propres..................... 543

Index des termes transcrits.................. 577

Index analytique $\ldots \ldots \ldots \ldots \ldots \ldots \ldots \ldots \ldots \ldots \ldots \ldots \ldots$

Planches ............................. 691

Explication des planches..................... 693

Table des figures.............................. 695

Table des matières du tome $I \ldots \ldots \ldots \ldots \ldots \ldots \ldots \ldots . \ldots 67$

Table des matières $\mathrm{du}$ tome II. ................. 701 

IMPRIMERIE F, PAILLART

ABBEVILLE

No d'impression : 3077 .

Dépot légal : 30 trimestre 1975 


